\title{
Mass spectrometry in nucleic acid, carbohydrate and steroid analysis
}

\author{
Bruce Jon Compton ${ }^{\mathrm{a}}$ and Gary Siuzdak ${ }^{\mathrm{b}, *}$ \\ ${ }^{\text {a } W a t e r s ~ C o r p o r a t i o n, ~} 34$ Maple Street, Milford, MA 01757, USA \\ ${ }^{\mathrm{b}}$ The Scripps Research Institute, 10550 North Torrey Pines Road, La Jolla, CA 92037, USA
}

\begin{abstract}
Mass spectrometry is now widely used in many areas of biomolecule analysis and this diversity is well represented by the analysis of oligonucleotides, carbohydrates and steroids. In this paper an overview of the common techniques used for analysis of these biomolecules is presented, including electrospray ionization (ESI), matrix-assisted laser desorption/ionization (MALDI), desorption/ionization on silicon (DIOS), and negative chemical ionization gas chromatography mass spectrometry (NCI GC/MS). Additionally, important aspects of biomolecule analysis, such as molecular weight determination, sequencing using tandem mass spectrometry and enzymes, precursor ion scanning, noncovalent interactions, and sensitivity, will be discussed.
\end{abstract}
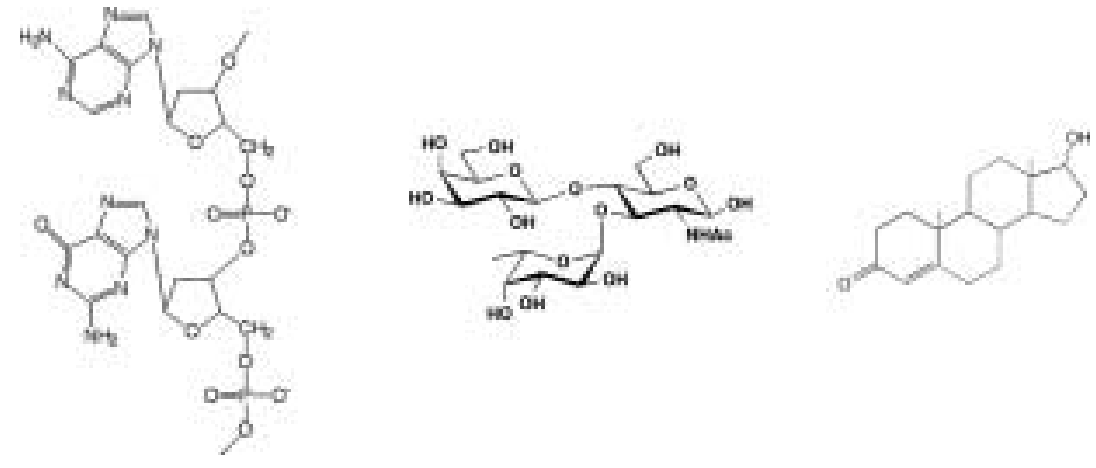

\section{Oligonucleotide analysis}

Oligonucleotides are routinely assembled using automated solid phase DNA synthesis. In general, this technique is highly efficient, resulting in stepwise coupling yields of nucleoside phosphoramidite monomers as high as $99 \%$. However, even with such efficient coupling reactions the theoretical yield for a $20 \mathrm{mer}$ is less than $90 \%$. Errors in synthesis can also occur, resulting in a further decrease in the overall yield. Therefore, synthetic oligonucleotides require confirmation of purity and identity, which can be troublesome since the impurities frequently coelute on HPLC. The most common technique for oligonucleotide analysis is MALDI-MS [1-3], given that it is comparatively tolerant of mixtures and impurities, however, ESI-MS and LC ESI-MS are also employed. In addition to structure conformation, mass spectrometry is also being developed as a diagnostic tool for single nucleotide polymorphorisms (SNP's) analysis.

\footnotetext{
*Corresponding author. E-mail: siuzdak@ scripps.edu.
} 


\subsection{Oligonucleotide analysis by MALDI-MS}

As mentioned above, MALDI-MS is typically the method of choice for intact oligonucleotide analysis. Figure 1 illustrates the analysis of an intact oligonucleotide by MALDI-MS. In addition to direct oligonucleotide analysis, it is possible with MALDI-MS to generate complete sequence information using an approach called "ladder sequencing", in which the results from different enzyme digestions of the oligonucleotide are combined [1]. The use of multiple enzymes, specifically bovine spleen phosphodiesterase and snake venom phosphodiesterase, yields a stepwise sequence of peaks that directly correlate to the oligonucleotide sequence from either the $5^{\prime}$ or $3^{\prime}$ end. For instance, exposure to a high enzyme concentration results in significant digestion of the oligonucleotide. Subsequent digests of the oligonucleotides at lower enzyme concentrations generate enough information to sequence the entire oligonucleotide (Fig. 2). The successively weaker enzyme solutions produce less digestion and therefore more information about the initial residues on the oligonucleotide termini. In MALDI-MS ladder sequencing experiments, no background signal was observed from either enzyme providing "clean" MS
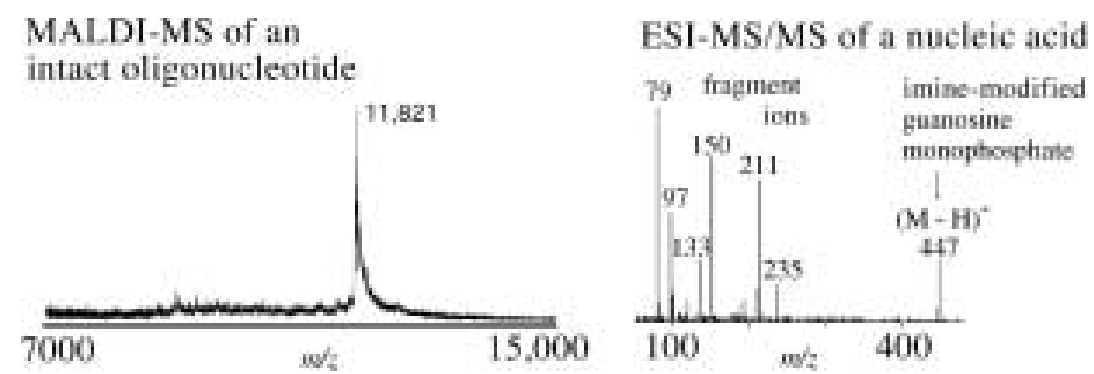

Fig. 1. MALDI mass spectrum of an oligonucleotide (37mer) and an ESI tandem mass spectrum of a nucleic acid. MALDI is particularly useful for oligonucleotide analysis because of its relative tolerance to impurities and sensitivity while ESI is useful for nucleic acids because of their small size.
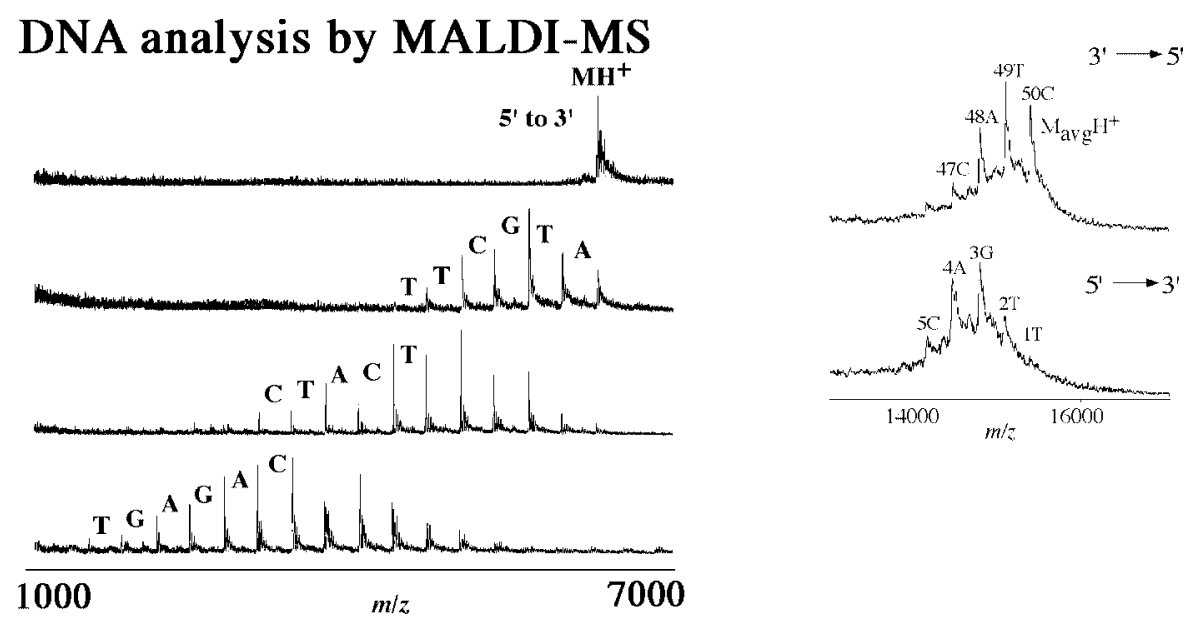

Fig. 2. MALDI-MS (positive ion) of a ladder sequence where the order of the peaks corresponds to the sequence. The oligonucleotide ladder sequence $5^{\prime}$ to $3^{\prime}$ is generated from digestion using enzyme bovine spleen phosphodiesterase and the ladder sequence $3^{\prime}$ to $5^{\prime}$ is generated using the enzyme snake venom phosphodiesterase. The combination of the two can generate complete sequence information. 
data, and the total amount of sample consumed was typically less than 2 nanomoles for the entire set of analyses (nine digests).

MALDI-MS ladder sequencing of a 50mer is shown in Fig. 2, which illustrates that approximately 5 residues from either the $5^{\prime}$ or $3^{\prime}$ end of the molecule were generated and observed. The signal intensities from the 50 and 40mer were typically less than those generated for the smaller oligonucleotides, which may account for the inability to detect more complete sections of the ladders. In addition, a significant amount of salt adducts were observed on the molecular ion, which resulted in significant peak broadening even after extensive desalting. An overview of the oligonucleotide MALDI-MS analysis and MALDI-MS ladder sequencing is provided in Table 1.

Another application of MALDI-MS is the analysis of a common type of-genetic heterogeneity in populations, known as single-nucleotide polymorphisms (SNP's), which have been linked to particular diseases. Specifically, MALDI time-of-flight (TOF) MS facilitates high-throughput mapping of SNP's due to its speed and high specificity. The time required for a typical MALDI-TOF-MS analysis is very short (less than ten seconds) and the detected masses are based on the absolute mass for the molecules being analyzed. Thus, this is a direct measurement technique that does not depend on secondary attributes of an analyte such as fluorescent tags, etc. Additionally, all the steps required for complete analysis can be automated. An example MALDI-TOF-MS spectrum of a SNP that has been implicated in hypertension is shown in Fig. 3.

Table 1

Characteristics of ESI and MALDI-MS oligonucleotide experiments [3]. It should be noted that if nanoESI-MS/MS were used to perform the ESI studies, considerably less material (femtomoles) would have been consumed

\begin{tabular}{ll}
\hline & Oligonucleotide analysis \\
\hline ESI-MS and ESI-MS/MS & MALDI-MS \\
\hline Picomole to femtomole sensitivity & Picomole to femtomole sensitivity \\
Range to about 100 residues for intact molecule & Range to about 200 residues for intact molecule \\
Range to about 6 residues for MS/MS complete sequence information & Range to about 30 residues for complete sequence \\
Usually only partial sequence information obtained & Often full sequence information obtained
\end{tabular}

\section{Comments:}

Interpretation of data is involved although computer deconvolution programs are available

\section{Comments:}

Partial sequence on the 50 mer and 40 mer complete sequence on the 2 mer-30mer

In an ESI study performed on representative oligonucleotides no sequence on an $18 \mathrm{mer}-50 \mathrm{mer}$ partial sequence on the $11 \mathrm{mer}$ complete sequence on the 2 mer-6mer

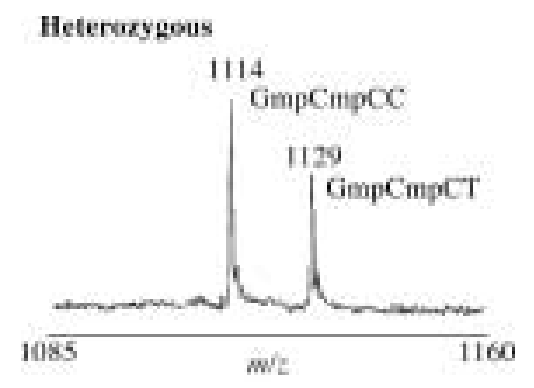

Fig. 3. Example data obtained from the high throughput MALDI-TOF-MS analysis of single nucleotide polymorphisms (SNP's) used in disease diagnostics. This individual has both forms (heterozygous). 


\subsection{Oligonucleotide analysis by ESI-MS}

Electrospray mass spectrometry is also a useful tool in the characterization of oligonucleotides $[3,4,7]$. Example applications of ESI-MS oligonucleotide analysis are shown in Figs 1 and 4 with the analysis of a single nucleic acid and a megaDalton DNA molecule, respectively. In general, for molecular weight characterization, ESI-MS can be quite informative with respect to purity and confirmation. It cannot be overstated that ESI-MS is usually more sensitive to impurities than other ionization techniques, and successful analysis typically requires rigorous desalting to obtain quality mass spectral data. To a lesser extent, the same is true of MALDI-MS, although impure samples can often be successfully analyzed by MALDI-MS and not by ESI-MS. Another unique feature of ESI-MS spectra is the generation of numerous multiply charged species (Figs 5 and 6), which again is due to adduct formation from contaminating cations. Conversely, MALDI-MS typically generates peaks that are dominated by the $1+$ charge state (Figs 1 and 2).

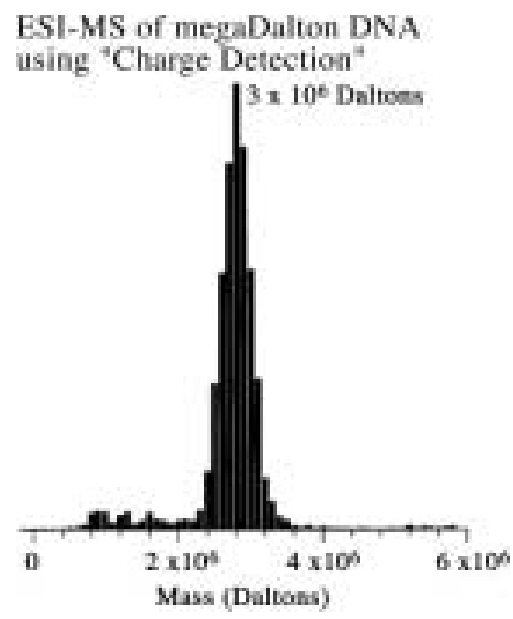

Fig. 4. An example of ESI-MS oligonucleotides analysis. Henry Benner has created an instrument (30) capable of analyzing megaDalton molecules (and even viruses) using ESI coupled to a special charge detection device that detects ions regardless of how big they are. Routine ESI-MS oligonucleotides analyses are typically limited to a size of up to 30,000 Daltons and detection is very sensitive to concentration, impurities, and solvent conditions.

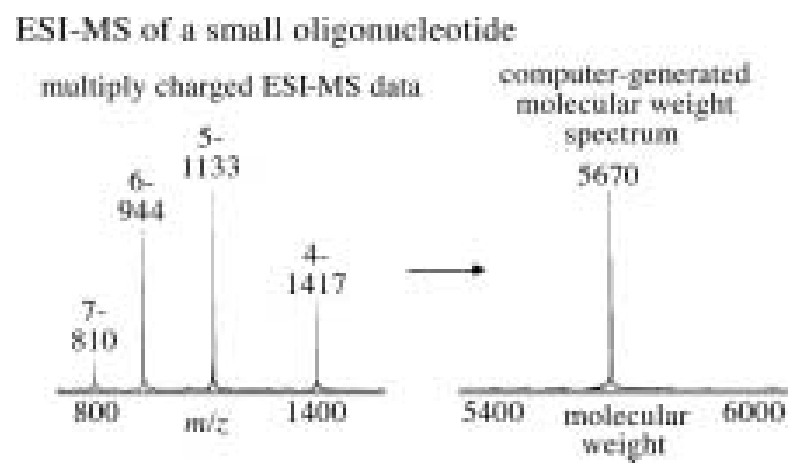

Fig. 5. Electrospray ionization (negative ion) mass spectrum of an oligonucleotide. The computer-generated molecular weight spectrum was produced from the mass spectral data. Complete removal of small cations such as sodium from the sample can facilitate analysis by eliminating multicharged states, thereby greatly simplifying spectra. 


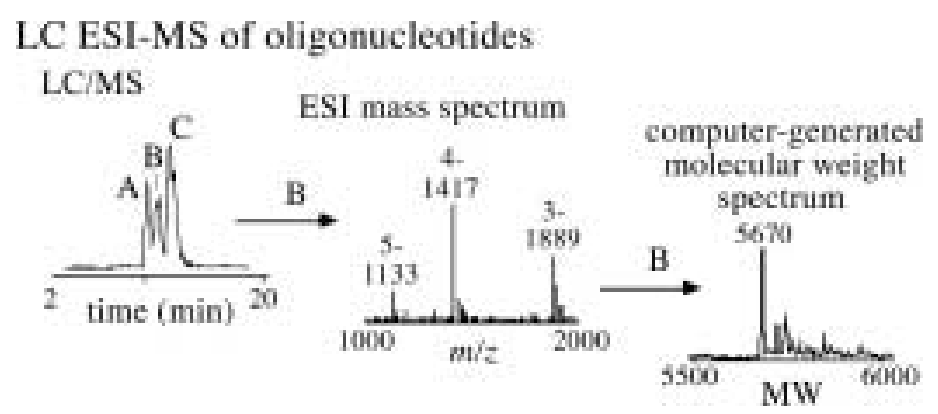

Fig. 6. The LC ESI-MS of three oligonucleotides, the ion chromatogram, $m / z$ data and the reconstructed molecular weight spectrum of the B oligonucleotide. Multiply charged ions representing negative charge states 3, 4, and 5 were observed.

Purification and characterization methods for oligonucleotides include high performance liquid chromatography (HPLC), polyacrylimide gel electrophoresis (PAGE), capillary electrophoresis and dimethoxytrityl oligonucleotide purification cartridges. The effectiveness of these techniques is well known, however, they cannot unequivocally identify oligonucleotide composition or impurities. ESI-MS, and the more recent application of HPLC-ESI-MS, provide enough information to verify base composition and purity. Direct ESI-MS analysis of unpurified oligonucleotides can give poor signals due to contaminating salts, therefore, the use of HPLC can increase sensitivity as it serves to remove these salts and separate other contaminants prior to MS analysis.

\subsection{Oligonucleotide analysis by electrospray tandem mass spectrometry}

In a set of simple experiments using an ESI collision-induced dissociation (CID) tandem mass spectrometry (MS/MS), the dissociation of oligonucleotides was investigated to determine how much sequence information the fragmentation patterns provide. ESI-MS/MS experiments were performed on 50, 40, 30, and 20mer oligonucleotides, and the samples were typically prepared in a 50:50 water/methanol solution. ESI-MS analysis gave excellent molecular ion signals corresponding to multiply charged states (in negative ion mode) and accurate total molecular weight information; however, ESI-M/MS ${ }^{2}$ provided virtually no sequence information on these oligonucleotides. These results were not surprising given the size of the molecules and the low energy collisions generated in the triple quadrupole mass spectrometers.

ESI-MS $^{2}$ experiments were also performed on smaller oligonucleotides including an 18, 11, 6, 4, 3, and 2 mer. All of these oligonucleotides produced excellent ESI-MS molecular ion signals in negative ion mode, while complete sequence information from ESI-MS/MS was possible only on the 6, 4, 3, and 2 mer (the entire sequence and cleavage site information of the 6mer (Fig. 7) and 4mer. It should be noted that interpretation of the ESI-MS/MS results was typically more labor intensive (as compared to ladder sequencing) because fragmentation can occur at multiple sites on the phosphate, sugar, and base of the oligonucleotides. In contrast, MALDI ladder sequencing of the 20,18, 11, and 6mer (Fig. 7) was straight forward, and complete sequence information was easily generated with excellent $\mathrm{S} / \mathrm{N}$ and mass accuracy. It was possible to generate complete sequence information for the $4 \mathrm{mer}$, $3 \mathrm{mer}$ and $2 \mathrm{mer}$ as well, however, the data were more challenging to interpret due to the background matrix interference in the low mass region. It should also be noted that in the oligonucleotide sequencing experiments neither ESI-MS/MS nor MALDI ladder sequencing were rigorously optimized to increase sensitivity and in general the amount of material consumed in the ladder sequencing experiments $(\sim 2 \mathrm{nmol})$ exceeded that of $\operatorname{ESI}_{-M S}^{2}(\sim 500 \mathrm{pmol})$. 


\section{ESI tandem mass spectrometry of an oligonucleotide}
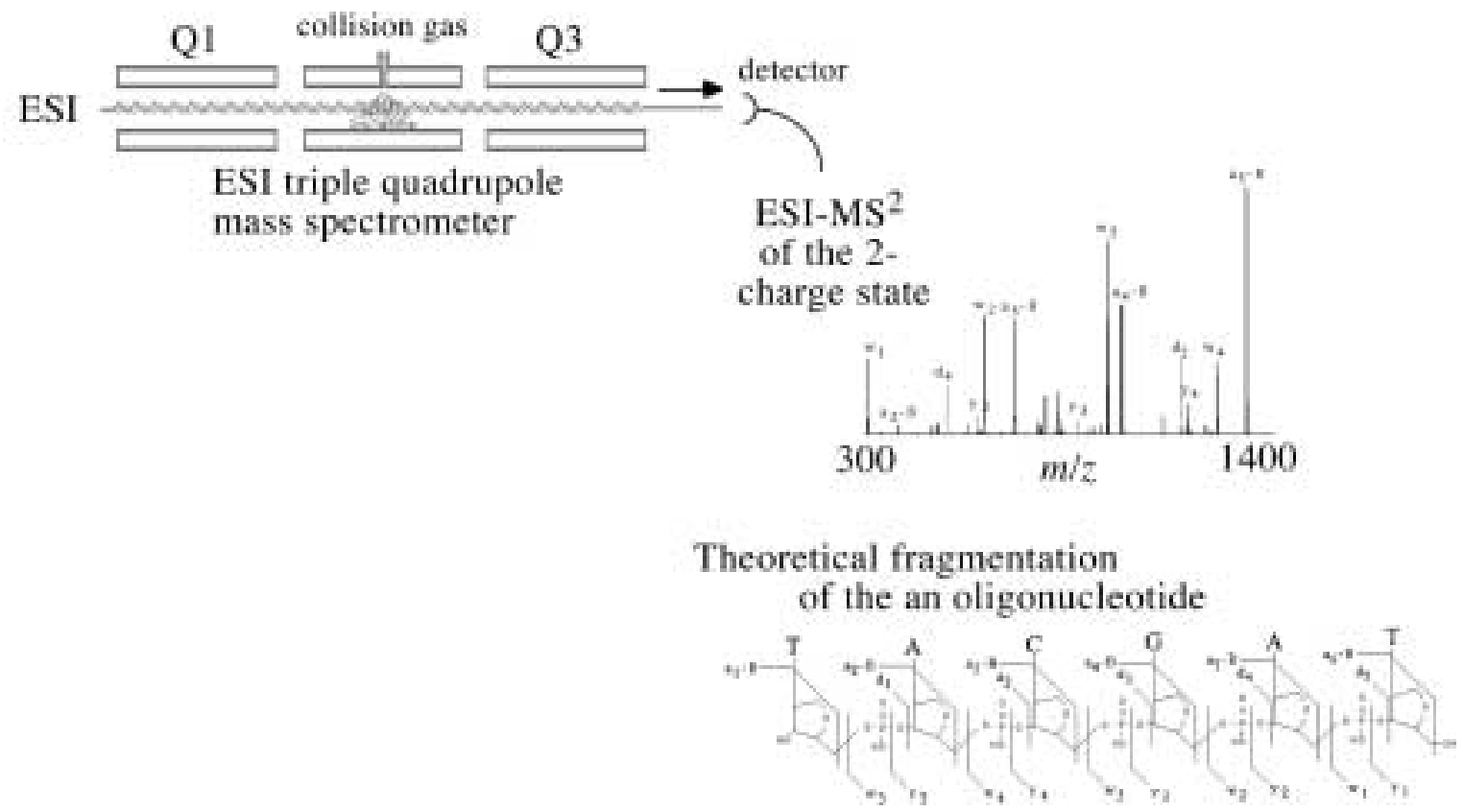

Fig. 7. ESI-MS/MS (negative ion) data generated on the 6 mer oligonucleotide $5^{\prime}$-TACGAT- $3^{\prime}$ using the collision-induced dissociation on a triple quadrupole mass spectrometer. The theoretical fragmentation of this molecule is also shown.

\section{Carbohydrate analysis}

Carbohydrates can be difficult to observe by mass spectrometry, yet they represent one of the largest and most important classes of biological molecules. Carbohydrates can be ionized in both positive ion and negative ion mode (depending on the molecule) to give $\mathrm{MH}^{+}, \mathrm{M}+$ alkali metal or ammonia, or proton abstraction $[\mathrm{M}-\mathrm{H}]^{-}$. The ionization mode is highly dependent on the type of sugar. For example, neutral sugars generally give the positive ion ( $\mathrm{M}+$ alkali metal ions) as the dominant with no significant formation of $\mathrm{MH}^{+}$. ESI-MS, MALDI-MS and DIOS-MS are all capable of producing spectra from a wide variety of sugars and have detection limits down to the femtomole level. In addition, the mass accuracy can be $10 \mathrm{ppm}$ or better depending on the mass analyzer. Fragmentation methods such as postsource decay, TOF-TOF, hybrid quadrupole time-of-flight (Qtof) and Fourier transform-ion cyclotron (FT) mass analyzers are now available and can provide useful structural information in the analysis of carbohydrates.

\subsection{Carbohydrates by MALDI-MS and DIOS-MS}

MALDI-MS analysis of carbohydrates typically yields the best spectra when using 2,5-dihydrobenzoic acid as a matrix. While both MALDI-MS and DIOS-MS are tolerant of contaminants such as salts and detergents, it is common that these contaminants have a significant detrimental effect on carbohydrates analysis. Although not necessary for the MALDI process, permethylation can be used to improve signal. However, complete permethylation is seldom achieved and therefore most researchers prefer to work with the underivatized sugars. 


\section{DIOS-MS of a Carbohydrate}

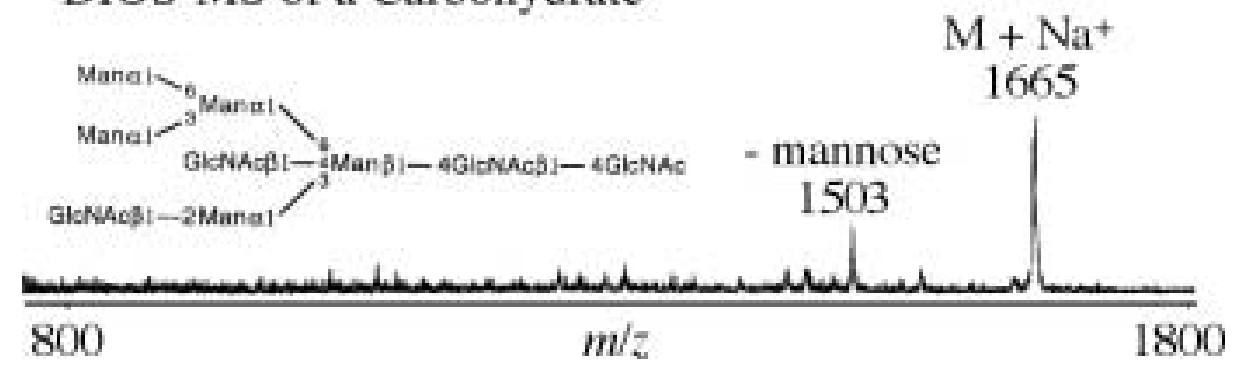

Fig. 8. Monitoring a stereospecific enzymatic reaction of a glycosidase on an N-linked carbohydrate with DIOS-MS. The reaction involved exoglycosidase activity of 1-3-(1-6)mannosyl-oligosaccharide $\alpha$-D-mannohydrolase (commonly known as mannosidase II). The reaction was performed at $37^{\circ} \mathrm{C}$ for 60 minutes directly on the porous silicon surface with 30 pmoles of carbohydrate and approximately 1.5 pmoles of enzyme.
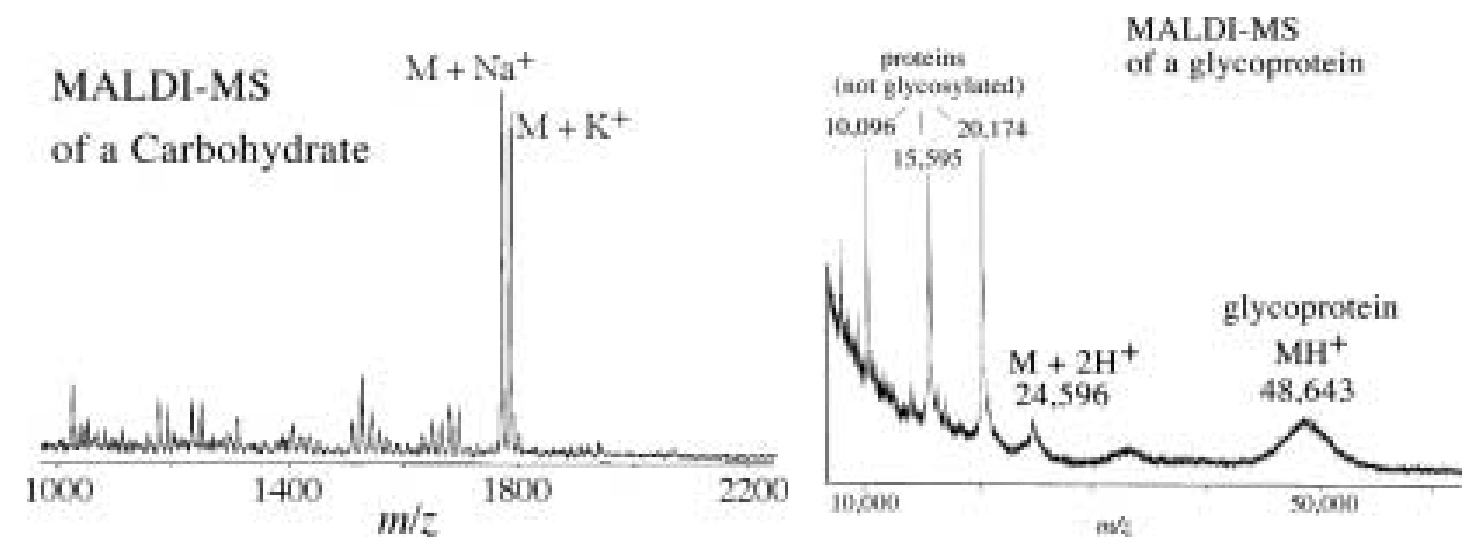

Fig. 9. MALDI-MS of a carbohydrate and a glycoprotein.

As shown in Fig. 8, DIOS-MS was used to monitor the exoglycosidase activity of 1-3-(1-6)mannosyloligosaccharide $\alpha$-D-mannohydrolase (commonly known as mannosidase II) on an N-linked carbohydrate. The enzyme (molecular weight 190,000 Daltons) preferentially removes the $1 \rightarrow 3$ linked mannose residue from the non-reducing terminus. Example MALDI-MS spectra of a carbohydrate and a glycoprotein are shown in Fig. 9. A significant broadness is observed in the glycoprotein peak, which comes largely from heterogeneity associated with glycosylation.

\subsection{Carbohydrate analysis by ESI}

While MALDI is quite popular for carbohydrate analysis, and in some cases preferential, the most common method of analyzing carbohydrates is ESI $[5,6,8]$. This may be due to the accessibility of ESI-MS instrumentation, the easier preparation of the sample for ESI, or the greater availability of ESI instruments coupled with tandem mass analysis.

\subsection{Monosaccharide analysis with ESI}

The simplest carbohydrates, monosaccharides, generally exhibit higher signal when analyzed with alkali cations present. In an effort to gain insight into the nature of the carbohydrate/alkali cation complex, a variety of ESI-MS and ESI-MS/MS experiments were performed with D-glucose, D-galactose, 

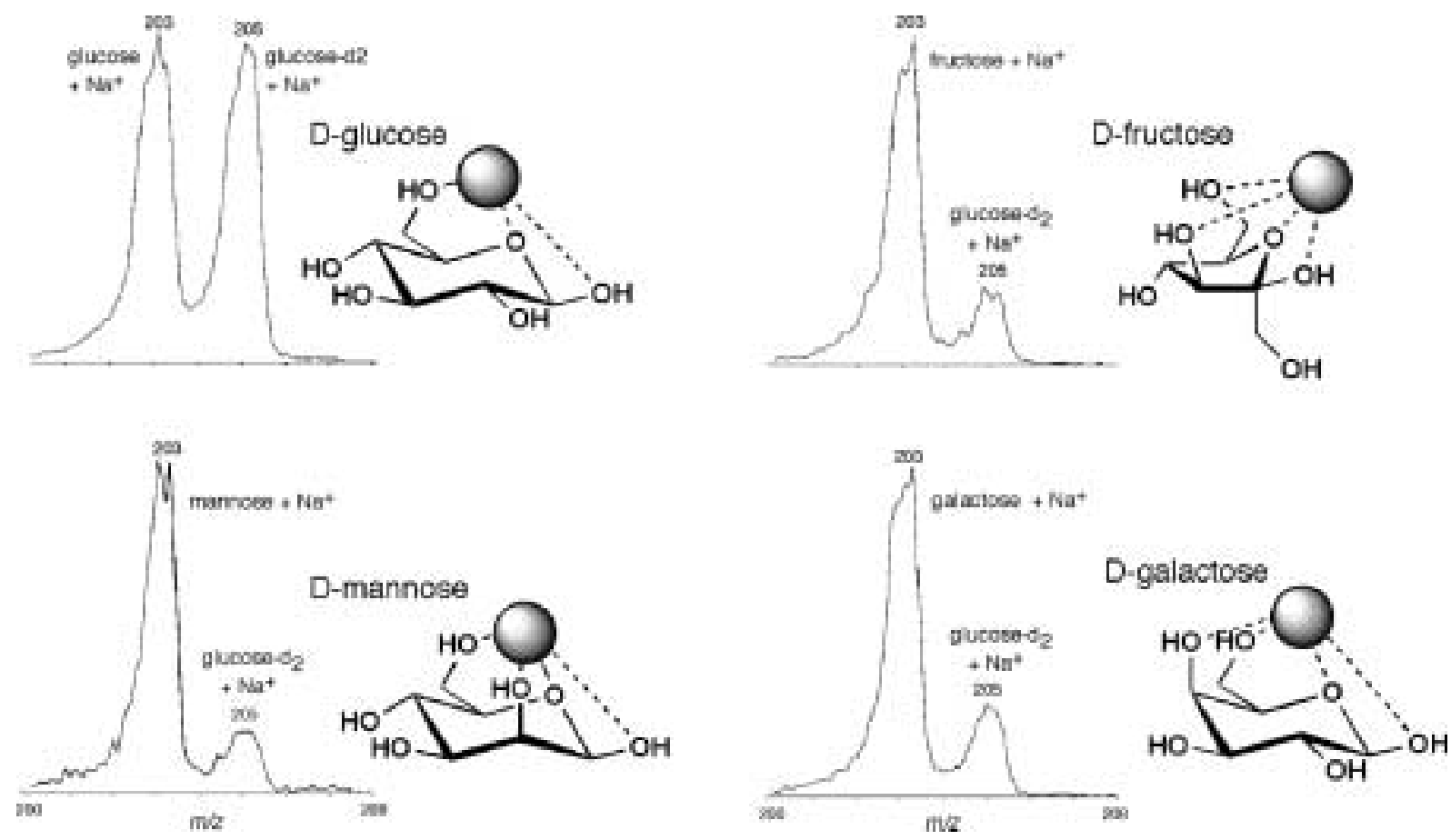

Fig. 10. ESI tandem mass spectral data comparing the sodium cation affinity of glucose and its isomers, fructose, galactose and mannose. The electrospray tandem mass spectrum of $\left[\mathrm{Na}^{+}+\mathrm{D}-6,6-\right.$ glucose- $\mathrm{d}_{2}+\mathrm{D}$-glucose $],\left[\mathrm{Na}^{+}+\mathrm{D}-6,6-\right.$ glucose- $_{2}$ + D-fructose], $\left[\mathrm{Na}^{+}+\right.$D-6,6-glucose- $\mathrm{d}_{2}+$ D-mannose], $\left[\mathrm{Na}^{+}+\right.$D-6,6-glucose- $\mathrm{d}_{2}+$ D-galactose] generated fragmentation spectra demonstrating D-fructose, D-mannose, and D-galactose have a significantly greater affinity for $\mathrm{Na}^{+}$than D-glucose. Structures were determined from both these ESI-MS/MS data and molecular modeling studies.

D-mannose, D-fructose, a deuterated analog of glucose, 6,6-D-glucose- $\mathrm{d}_{2}$, and the alkali cations $\mathrm{Na}^{+}$, $\mathrm{K}^{+}, \mathrm{Rb}^{+}$, and $\mathrm{Cs}^{+}$. ESI-MS/MS experiments of the monosaccharides bound to the cation generated a distinctive fragmentation pattern which indicated dissociation of only the alkali cation with no significant cleavage of covalent bonds. The three monosaccharides, galactose, fructose, and mannose, generated monosaccharide/cation-to-cation intensity ratios such that $\mathrm{Na}^{+}>\mathrm{K}^{+}>\mathrm{Rb}^{+}>\mathrm{Cs}^{+}$. This trend suggests that as the cation's atomic radius increases, the association with its host monosaccharide decreases. Interestingly, the results for D-glucose were similar, however, glucose had a lower affinity for $\mathrm{Na}^{+}$. The discrepancy in $\mathrm{Na}^{+}$affinity between glucose and the three other monosaccharides indicates that their different isomeric conformations might influence the ability of the alkali ions to complex the monosaccharides resulting in preferential cation binding (Fig. 10).

Additional MS/MS experiments were performed on the monosaccharide heterodimer/cation complexes to further investigate preferential cation binding and determine which monosaccharide had the greater cation affinity. The fragmentation analysis of the heterodimer/cation complex typically produced the [monosaccharide $+\mathrm{Na}]^{+},\left[6,6-\mathrm{D} \text {-glucose- } \mathrm{d}_{2}+\mathrm{Na}\right]^{+}$, and the precursor ion, [monosaccharide $+6,6-$ D-glucose- $\left.\mathrm{d}_{2}+\mathrm{Na}\right]^{+}$. The MS/MS analysis of the heterodimer complexes demonstrated significant preferential association to galactose, mannose and fructose as shown in Fig. 10. Space filling models of the monosaccharide, as well as energy minimization calculations, further revealed that D-galactose, D-mannose, and D-fructose bound $\mathrm{Na}^{+}$through a tetradentate complex while $\beta$-D-glucose used a tridentate complex (Fig. 10), which is consistent with the ESI-MS/MS data. 


\subsection{Complex carbohydrate analysis with ESI}

Sialyl Lewis $\mathrm{x}\left(\mathrm{SLe}^{\mathrm{x}}\right)$ is a carbohydrate that exists on the surface of leukocytes (white blood cells) and is recognized as a ligand in the calcium mediated adhesion between leukocytes and endothelial (blood vessel) cells. SLe $\mathrm{e}^{\mathrm{x}}$ readily generates ions in the positive and negative ionization modes including $\left[\mathrm{SLe}^{\mathrm{x}}+\mathrm{Ca}-\mathrm{H}\right]^{+},\left[\mathrm{SLe}^{\mathrm{x}}+\mathrm{Na}\right]^{+}$, and $\left[\mathrm{SLe}^{\mathrm{x}}-\mathrm{H}\right]^{-}$. Analysis of $\mathrm{SLe}^{\mathrm{x}}$ was performed using the MS/MS collision-induced dissociation (CID) capabilities of an ESI triple quadrupole mass spectrometer. Collisional activation of the $\mathrm{Ca}^{2+}$ complex, $\left[\mathrm{SLe}^{\mathrm{x}}+\mathrm{Ca}-\mathrm{H}\right]^{+}$, resulted in fragmentation with a characteristic loss of both fucose and sialic acid as the most abundant fragment ion (Fig. 11). The collisional activation of the precursor anion, $\left[\mathrm{SLe}^{\mathrm{x}}-\mathrm{H}\right]^{-}$, resulted in loss of $\mathrm{Le}^{\mathrm{x}}$, leaving only the sialic acid. $\mathrm{MS}^{2}$ analysis of the monovalent cation complex, $\left[\mathrm{SLe}^{\mathrm{x}}+\mathrm{Na}\right]^{+}$, resulted in fragmentation primarily through loss of sialic acid with some additional loss of fucose.
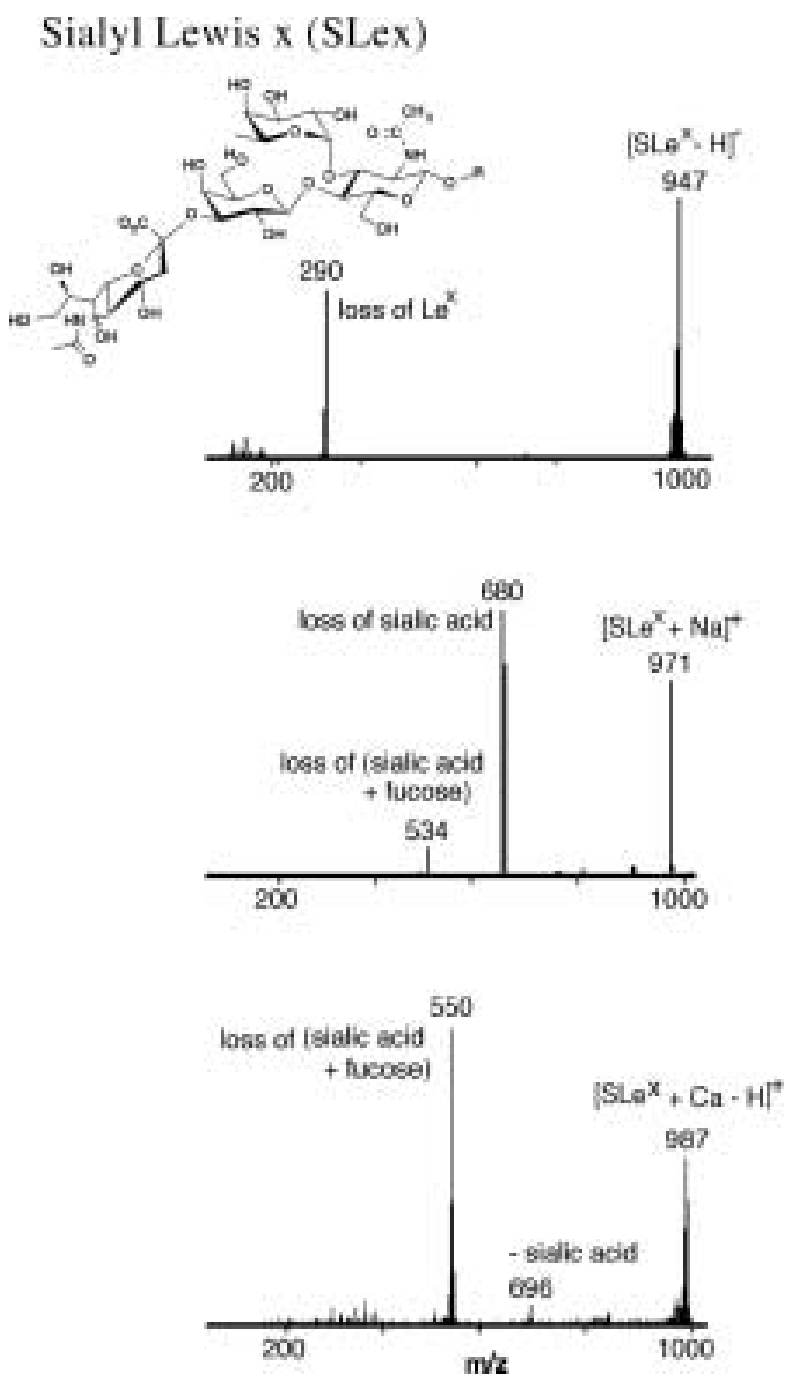

Fig. 11. Sialyl Lewis $x\left(\mathrm{SLe}^{\mathrm{x}}\right) \mathrm{MS} / \mathrm{MS}$ of SLe ${ }^{\mathrm{x}}$ : (top) negative ion fragmentation of $\left[\mathrm{SLe}^{\mathrm{x}}-\mathrm{H}\right]^{-}$, (middle) positive ion fragmentation of $\left[\mathrm{SLe}^{\mathrm{x}}+\mathrm{Na}\right]^{+}$, and (bottom) positive ion fragmentation of $\left[\mathrm{SLe}^{\mathrm{x}}+\mathrm{Ca}-\mathrm{H}\right]^{+}$. 


\subsection{Analysis of noncovalent carbohydrate interactions with ESI-MS}

$\mathrm{Le}^{\mathrm{x}}$ glycosphingolipids exist on cell surfaces and often exhibit extreme heterogeneity in their carbohydrate structures [10]. The availability of pure synthetic glycosphingolipids and the capabilities of ESI-MS ${ }^{2}$ allowed for the investigation of calcium mediated carbohydrate/carbohydrate interactions on the cell surface, which has been suggested to be precursor to cell-cell interactions.

During the analysis of these molecules it was observed that the $\mathrm{Le}^{\mathrm{x}}$ glycosphingolipid underwent significant homodimerization in the presence of calcium. In this process, a single $\mathrm{Ca}^{+2}$ cation binds the $\mathrm{Le}^{\mathrm{x}}$ portion of the glycosphingolipid to promote association to form a homodimer. This associative behavior was specific for $\mathrm{Ca}^{+2}$ and, interestingly, was not observed in the presence of monovalent cations.

To further investigate the moieties responsible for $\mathrm{Ca}^{+2}$ complexation in the associated $\mathrm{Le}^{\mathrm{x}}-\mathrm{LacCer}$ oligomers, MS/MS experiments were performed on the $\left[2 \mathrm{Le}^{\mathrm{x}}-\mathrm{LacCer}+\mathrm{Ca}^{+2}\right]^{+2}$ dimers. The resulting spectra indicated a neutral loss of covalently and noncovalently bound species as shown in Fig. 12. The CID mass spectra of the dimer produced six predominant fragment ions, two of which correspond to the loss of the ceramide moiety through either direct loss of Cer, ${ }^{\mathrm{d}} \mathrm{B}_{4 \alpha}$, or GalCer loss, ${ }^{\mathrm{d}} \mathrm{C}_{3 \alpha}$. The most predominant fragment was a loss of fucose, ${ }^{\mathrm{d}} \mathrm{B}_{1 \beta}$, from the dimer. Additional fragments correspond to the fucose loss from the monomer, ${ }^{m} \mathrm{~B}_{1 \beta}$, and the loss of two fucose residues from the intact dimer, ${ }^{\mathrm{d}} \mathrm{B}_{1 \beta \beta^{\prime}}$. These results indicate that the $\mathrm{Ca}^{2+}$ complexes with the sugar and further suggests that the Cer and GalCer functionalities may not perform an essential role in stabilizing the dimer. The ions observed in the CID mass analysis of the monomer corresponded to the loss of the GalCer and fucose moieties, indicating that $\mathrm{Ca}^{+2}$ may be bound to the Glc-Le ${ }^{\mathrm{x}}$ sugar. Overall carbohydrates can be challenging to an-

\section{ESI-MS/MS of

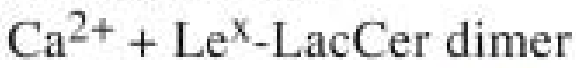

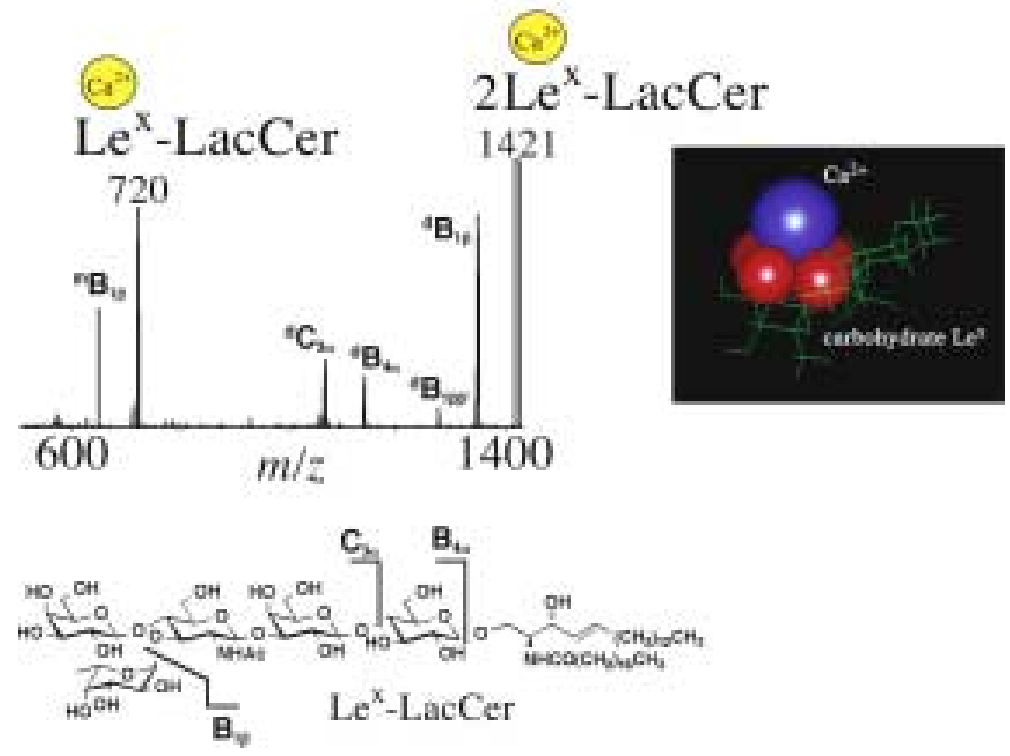

Fig. 12. CID mass spectrum of the dimer $\left[2 \mathrm{Le}^{\mathrm{x}}-\mathrm{LacCer}+\mathrm{Ca}^{+2}\right]^{+2}(m / z 1421)$ including fragmentation nomenclature; ${ }^{\mathrm{d}}$ designates that the fragment ion includes the noncovalent dimer, ${ }^{\mathrm{m}}$ designates that the fragment ion includes only the monomer and is no longer noncovalently bound to the other $\mathrm{Le}^{\mathrm{x}}-\mathrm{LacCer}$. Inset is a energy minimized space-filling model of the calcium interactions with $\mathrm{Le}^{\mathrm{x}}$. 
alyze with mass spectrometry, yet, whether they are simple monosaccharides or more complex, ESI-MS, MALDI-MS and DIOS-MS have proven successful.

\section{Steroid analysis}

The detection and analysis of steroids in tissues and biofluids such as cerebrospinal fluid, urine, and blood have long posed a significant technical challenge due to their low concentrations, varied polarity, and presence in complex mixtures. Normally, many samples must be pooled to acquire enough material for the detection and study of steroids and their metabolites, traditionally by gas chromatography (GC), high performance liquid chromatography (HPLC), gas chromatography/mass spectrometry (GC/MS), and electrospray ionization (ESI) liquid chromatography/mass spectrometry (LC/MS).

A standard mass spectrometric approach to analyzing steroids has been by negative chemical ionization GC/NCI-MS [11,12]. NCI is performed in combination with derivatization of the molecule to enhance its ionization properties. Although GC/MS NCI is a very useful tool, the limitations to this approach include extensive chemical preparation time and relative instability of the derivative. Steroid analysis with the newer ESI approaches has been complicated by the limited capability of mass spectrometers to ionize these compounds.

In order to make the DIOS [14], ESI [13], or GC/NCI-MS approaches more effective it is common to focus on derivatization techniques such as sulfation.
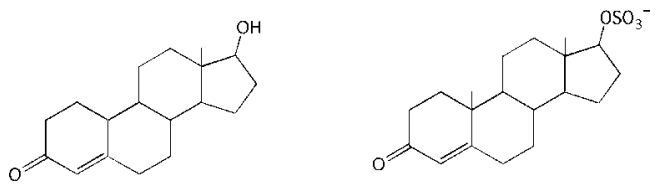

Testosterone as an unconjugated steroid (left) and its sulfated conjugate (right).

\subsection{Steroids by GC negative chemical ionization-MS}

Negative chemical ionization in GC/MS can be a very efficient and sensitive approach toward detecting low level quantities of compounds (Fig. 13). In negative chemical ionization, a buffer gas (such as methane) reduces the energy of electrons in the electron beam ultimately allowing for resonant electron capture by the analyte molecules. The buffer gas can also reduce fragmentation. Some of the benefits include high sensitivity because of efficient ionization, less fragmentation than positive ion electron ionization or chemical ionization. Some of the limitations are that most volatile compounds do not efficiently produce negative ions and therefore require derivatization to facilitate electron capture.

Pentafluorobenzyloxime/trimethyl-silyl-ether derivatives are also commonly used to facilitate electron capture and therefore enhance mass spectrometric analysis. Additionally, to further enhance sensitivity the mass spectrometer is operated in a selective ion-monitoring mode (SIM) which allows for picograms of steroids to be quantified from biological extracts. GC NCI MS for steroid analysis is still quite commonly used in many areas of research.

\subsection{Steroid analysis by DIOS}

A simple example of analyzing sulfated steroids by DIOS-MS is demonstrated here where $100 \mu \mathrm{l}$ of urine was first extracted with $600 \mu \mathrm{l}$ of diethyl ether/hexane $(90: 10 \mathrm{v} / \mathrm{v})$ and then with $600 \mu \mathrm{l}$ chloroform/butanol $(50: 50 \mathrm{v} / \mathrm{v})$. The collected organic fractions were dried and resuspended in $70 \% / 30 \%$ 


\section{GC - Negative Chemical Ionization MS}
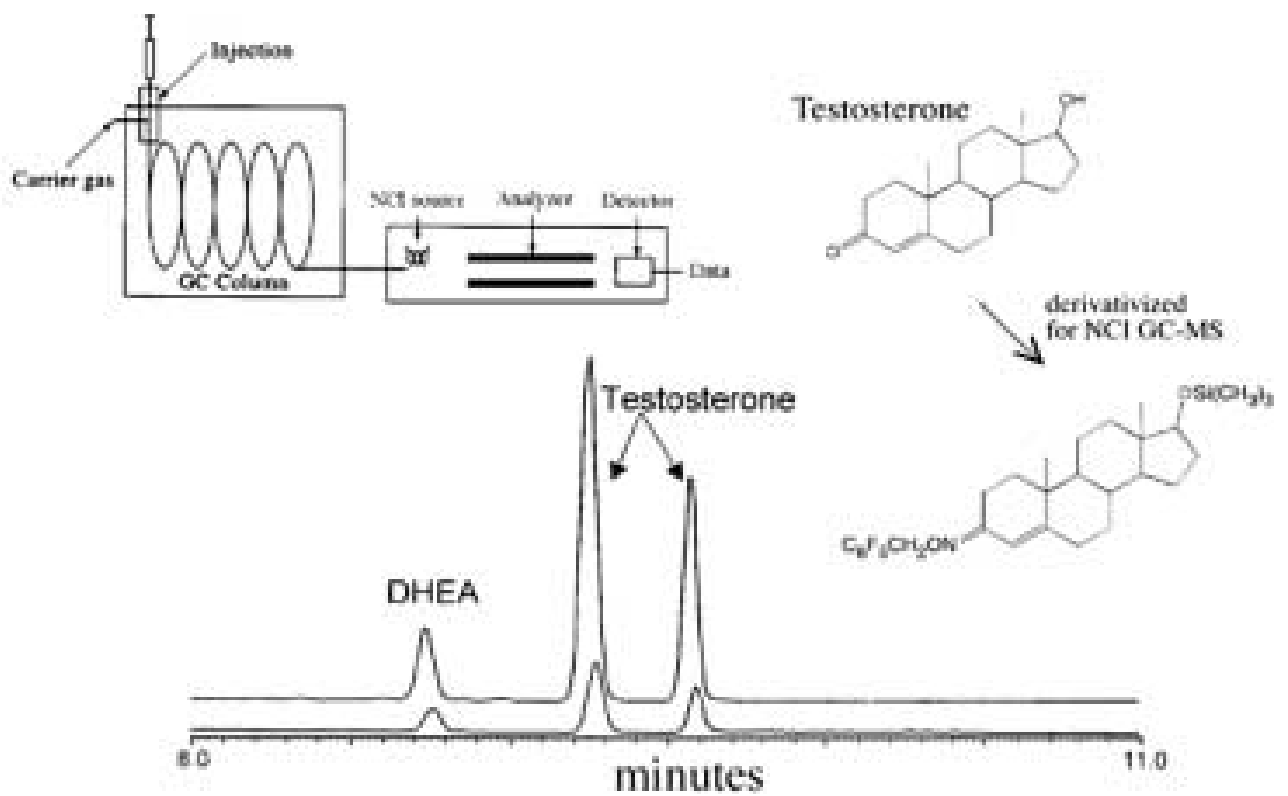

Fig. 13. DHEA and testosterone $(0.5 \mathrm{ng})$ were quantified using $m / z 535$ ion. The deuterated internal standards, DHEA-d3 and testosterone-d3 were monitored at $m / z$ 538. Adapted from [11].
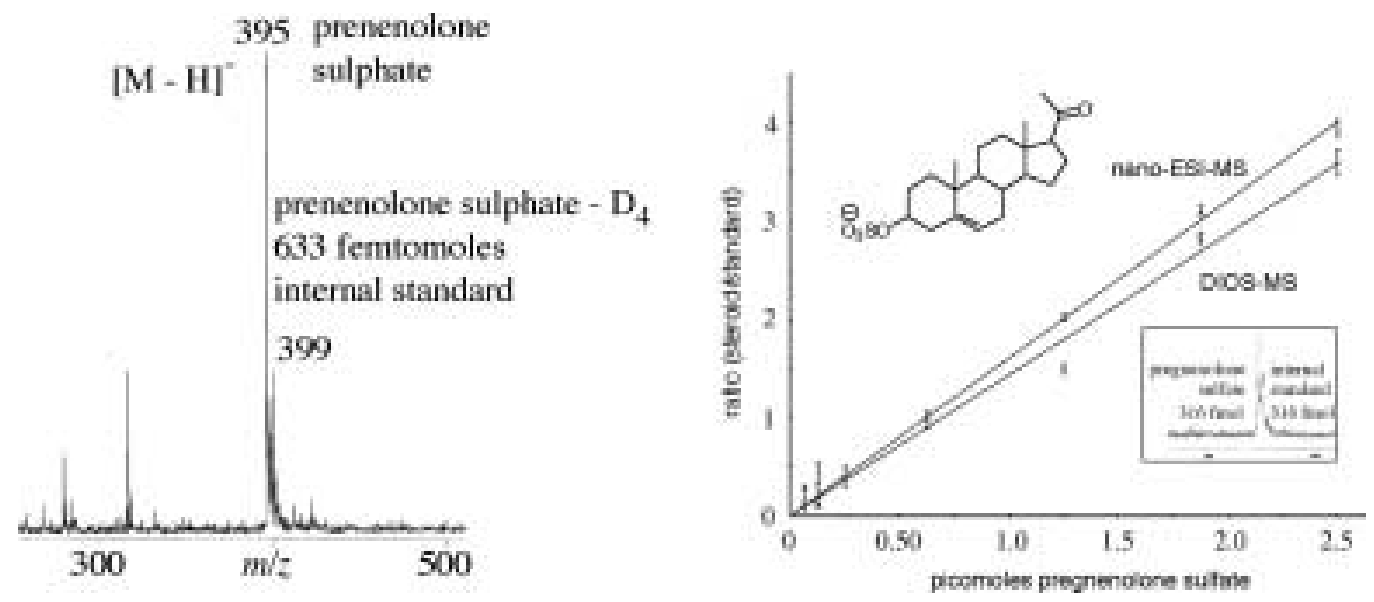

Fig. 14. Examples of DIOS-MS spectra including a sulfated steroid (negative ionization mode (1 pmol), quantitative analysis of the sulphated steroid was demonstrated using DIOS-MS and nanoESI precursor ion scanning.

methanol/water with the addition of an internal standard. Such modest sample preparation methods are generally needed to rid biological samples of high concentrations of salts and other contaminants. In this example $316 \mathrm{fmol}$ of the internal standard (pregnenolone- $d 4$ ) (Fig. 14) was used to generate the calibration curve, and not surprisingly male urine samples were found to contain testosterone sulfate, androsterone sulfate, 3-hydroxy-5-androstan-17-one sulfate, or 17-hydroxy-5-androstan-3-one sulfate, and 3-hydroxy-17-oxoandrost-5-en-19-al sulfate. 


\subsection{Steroids by ESI}

NanoESI mass spectrometry is also an accurate and sensitive analytical technique for the detection, quantitation, and structural confirmation of steroid sulfates found in biofluids. Combined with precursor ion scanning, nanoESI provides for low femtomole to attomole detection limits for charged compounds. By comparison, conventional ESI and APCI is far less sensitive (high picomoles), consume more material (30-80 $\mu \mathrm{l})$, and have the possibility of carryover from previous samples which can interfere with detection and quantitation. While MALDI is relatively sensitive (low picomoles), matrix interference in the mass ranges below 500 Daltons make it an undesirable approach. The small amount of sample consumed in nanoESI experiments suggest that nanoLC/MS, can further increase sensitivity and eliminate potential biological matrix effects. Nanoelectrospray ionization (nanoESI) mass spectrometry was performed on naturally occurring steroid sulfates and unconjugated steroids derivatized to their sulfate esters using precursor ion monitoring.

NanoESI is accomplished by loading $\mu \mathrm{l}$ volumes of sample solution into a glass capillary needle. Various types of capillaries are available, sealed or non-sealed, and in multiple sizes with different types of coatings for different types of analyses. In the instance of sealed capillaries, the needle is opened by gently touching the closed end against the orifice plate of the mass spectrometer to produce an opening with a diameter of approximately $10 \mu \mathrm{m}$. Once opened, the needle is positioned in front of the orifice at a distance of 1-2 mm. The sample is directed into the mass spectrometer by a gas-tight syringe that allows

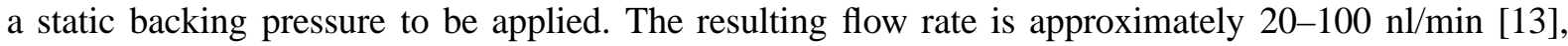
allowing microliter sample volumes to be examined for extended periods of time with a minimal amount of sample consumed. One microliter of sample can last up to 30 minutes depending on the pressure applied to the syringe.

To adapt nanoESI for steroid analysis we have employed precursor ion scanning and sulfation [13] of steroids. The utility of precursor ion scanning for the selective detection of small molecules is well recognized. With precursor ion scanning, the sulfate fragment $\mathrm{m} / z 97$ is used to generate spectra of its precursors, or "parent" ions. By employing precursor ion scanning, the interference from chemical noise is greatly reduced, thereby enhancing the signal-to-noise ratio. In negative nanoESI, the anionic species of steroid sulfates is observed and can be detected at concentrations lower than the protonated $[\mathrm{M}+\mathrm{H}]^{+}$or $\left[\mathrm{M}-\mathrm{H}_{2} \mathrm{O}+\mathrm{H}\right]^{+}$species of unconjugated steroids in positive mode. The formation of a

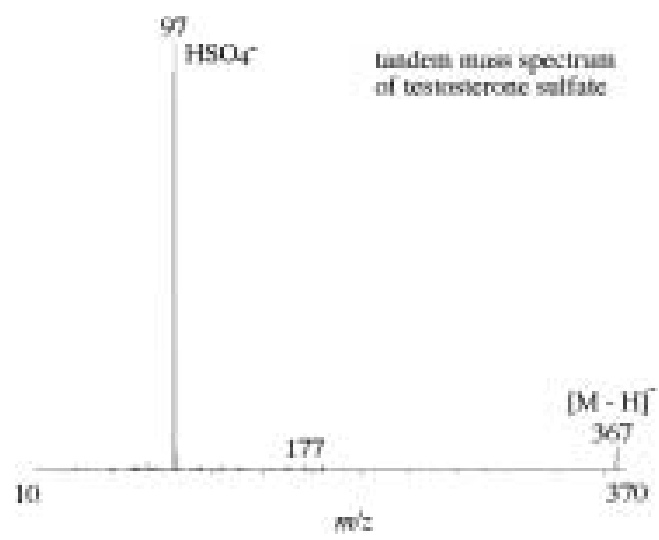

Fig. 15. Negative ion nanoESI MS/MS spectrum of testosterone sulfate $(m / z 367)$ from extract of male bonobo urine. Base peak $(m / z 97)$ is the sulfate anion $\left[\mathrm{HSO}_{4}^{-}\right]$. 


\section{Precursor ion scanning with a triple quadrupole}

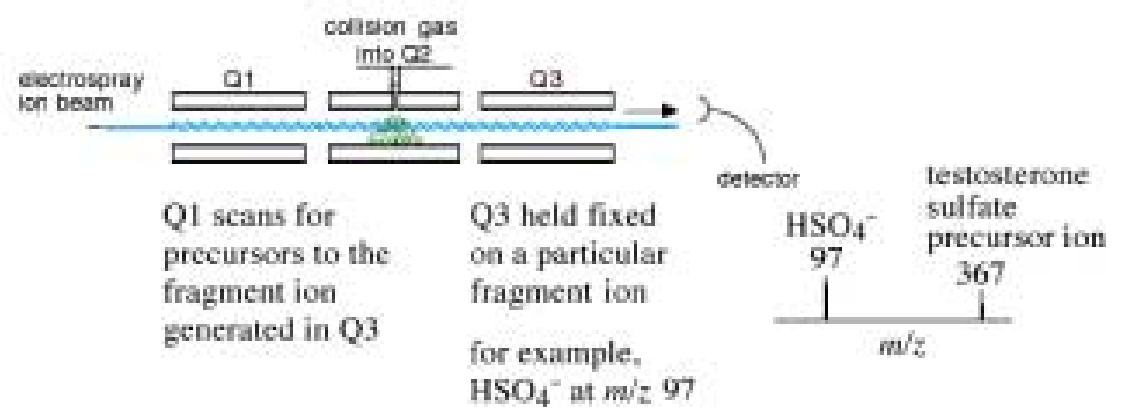

Fig. 16. Precursor ion scanning illustrating that Q3 is held fixed on a particular fragment ion and Q1 is scanned to find the precursors to the fragment ion. In this case the sulfate anion $\left[\mathrm{HSO}_{4}^{-}\right]$at $\mathrm{m} / z 97$ is the fragment and testosterone sulfate $(m / z 367)$ is the precursor.

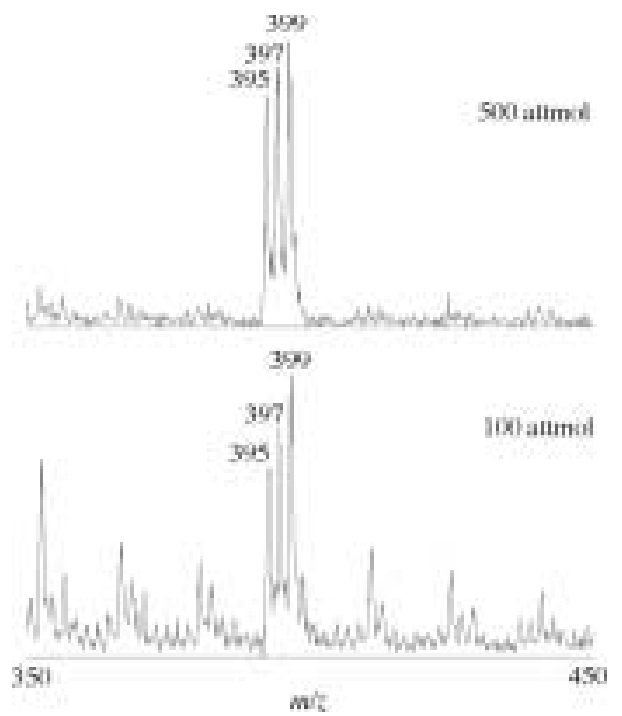

Fig. 17. (Top) Negative ion nanoESI mass spectra (precursor ion scanning) of a mixture of pregnenolone sulfate $(m / z 395)$, allopregnanalone sulfate $\left(m / z\right.$ 397), and $\mathrm{d}_{4}$-pregnenolone sulfate $(m / z 399)$ at 500 attmol/ $\mu \mathrm{l}$. (Bottom) The same analysis performed at a concentration of $100 \mathrm{attmol} / \mu \mathrm{l}$. Both spectra demonstrate the sensitivity of nanoESI using precursor ion scan negative ionization. The limit of detection from CSF and artificial CSF was found to be $200 \mathrm{attmol} / \mu \mathrm{l}$.

sulfate functional group not only increases sensitivity, but also makes precursor ion scanning possible because the sulfate $\left(\mathrm{HSO}_{4}^{-}\right)$fragment ion is observed in collision-induced dissociation (CID) tandem mass spectrometry (Figs 15, 16). The combination of enhancements offered by sulfation and precursor ion scanning have allowed steroid sensitivity levels to approach those necessary for neurosteroid analysis.

To demonstrate the sensitivity afforded sulfated steroid analysis by nanoESI and precursor ion scanning, we established a limit of detection in the attomole range using a mixture of three sulfated steroid standards. A mixture of pregnenolone sulfate, allopregnanalone sulfate, and $\mathrm{d}_{4}$-pregnenolone sulfate was prepared with a concentration of $2.5 \mu \mathrm{mol} / \mu \mathrm{l}(1.0 \mathrm{mg} / \mathrm{ml})$ for each steroid. This solution was diluted by serial dilution to concentrations of $1.0 \mathrm{fmol} / \mu \mathrm{l}, 500 \mathrm{attmol} / \mu \mathrm{l}, 100 \mathrm{attmol} / \mu \mathrm{l}$, and $50 \mathrm{attmol} / \mu \mathrm{l}$. Single microliters of each solution were loaded into glass capillaries and analyzed by nanoESI using precursor 
ion scanning, with 50-200 nanoliters consumed per analysis. The limit of detection was found to be $100 \mathrm{attmol} / \mu \mathrm{l}$ with less than $20 \mathrm{attmol}$ consumed (Fig. 17). Steroids were detectable at the $50 \mathrm{attmol} / \mu \mathrm{l}$ concentration, but interference from background noise made the spectrum less distinct than that of the $100 \mathrm{attmol} / \mu \mathrm{l}$ solution. A second study was performed which analyzed extracts of the same steroid mixture from artificial CSF and urine using the aforementioned extraction procedure. The result of these experiments was a detection limit of $200 \mathrm{attmol} / \mu \mathrm{l}$, with less than 40 attmol consumed. Interestingly, the fact that only $20 \%$ of the sample was actually consumed during these experiments offers opportunities for employing nanoLC/MS for more profound studies involving steroids and their metabolic pathways, including the investigation of neurosteroids.

\section{Summary}

Mass spectrometry is being applied to a wide variety of molecules and this overview of its capabilities further accentuates this fact with the analysis of molecules ranging in chemical character as well as mass, demonstrating analyses on compounds of mass 180 Daltons to 3 million Daltons.

\section{References}

[1] U. Pieles, W. Zurcher, M. Schar and H.E. Moser, Matrix-assisted laser desorption ionization time-of-flight mass spectrometry: a powerful tool for the mass and sequence analysis of natural and modified oligonucleotides, Nucleic Acids Research 21 (1993), 3191-3196.

[2] I.P. Smirnov, M.T. Roskey, P. Juhasz, E.J. Takach, S.A. Martin and L.A. Haff, Analytical Biochemistry 238 (1996), 19-25.

[3] R.O. David, J.Y. Wu, Q. Phung and G. Siuzdak, Aspects of oligonucleotide and nucleic acid sequencing with MALDI and electrospray mass spectrometry, Bioorganic and Medicinical Chemistry 6 (1998), 1547-1554.

[4] J.C. Schultz, C.A. Hack and W.H. Benner, Mass determination of megadalton-DNA electrospray ions using charge detection mass spectrometry, J. Am. Soc. Mass Spectrom. 9 (1998), 305-313.

[5] G. Siuzdak, Y. Ichikawa, B. Munoz, T.J. Caulfield, C.-H. Wong and K.C. Nicolaou, Evidence of $\mathrm{Ca}^{+2}$-dependent carbohydrate association through ion spray MS, Journal of the American Chemical Society 115 (1993), 2877-2881.

[6] G. Siuzdak, Z.-L. Zheng, J.Y. Ramphal, Y. Ichikawa, K.C. Nicolaou, F.C.A. Gaeta, K.S. Chatman and C.-H. Wong, Examination of the sialyl Lewis X calcium complex by electrospray mass spectrometry, Bioorganic and Medicinal Chemistry Letters 4 (1994), 2863-2866.

[7] B. Bothner, K. Chatman, M. Sarkisian and G. Siuzdak, Liquid chromatography mass spectrometry of antisense oligonucleotides, Bioorganic and Medicinal Chemistry Letters 5(23) (1995), 2863-2868.

[8] B. Bothner, L. Carmitchel, K. Staniszewski, M. Sonderegger and G. Siuzdak, Biomolecule structure characterization in the gas phase using mass spectrometry, Spectroscopy 16 (2002), 71-79.

[9] G. Siuzdak, Mass Spectrometry for Biotechnology, Academic Press, San Diego, 1996.

[10] N. Kojima and S. Hakomori, Specific interaction between gangliotriaosylceramide (Gg3) and sialosyllactosylceramide (GM3) as a basis for specific cellular recognition between lymphoma and melanoma cells, J. Biol. Chem. 264 (1989), 20159-29162.

[11] M. Vallee, J.D. Rivera, G.F. Koob, R.H. Purdy and R.L. Fitzgerald, Quantification of neurosteroids in rat plasma and brain following swim stress and allopregnanolone administration using negative chemical ionization gas chromatography/mass spectrometry, Anal. Biochem. 287 (2000), 153-166.

[12] Alomary, Vallée, O'Dell, Koob, Purdy and Fitzgerald Acutely-administered ethanol participates in testosterone synthesis and increases testosterone in rat brain, Alcohol Clin. Exp. Res. 27 (2003), 38-43.

[13] K.S. Chatman, T. Hollenbeck, L. Hagey, M. Vallee, R. Purdy, F. Weiss and G. Siuzdak, Nanoelectrospray mass spectrometry and precursor ion monitoring for quantitative steroid analysis and attomole sensitivity, Analytical Chemistry 71 (1999), 2358-2363.

[14] Z. Shen, J.J. Thomas, C. Averbuj, K.M. Broo, M. Engelhard, J.E. Crowell, M.G. Finn and G. Siuzdak, Porous silicon as a versatile platform for laser desorption/ionization mass spectrometry, Analytical Chemistry 33 (2001), 179-187. 


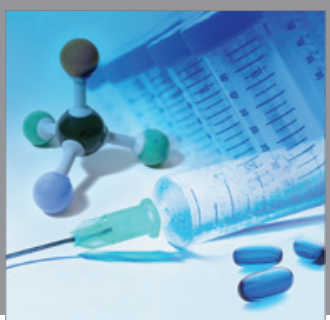

International Journal of

Medicinal Chemistry

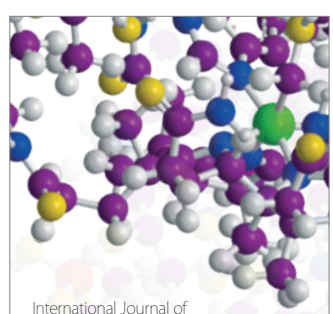

Carbohydrate Chemistry

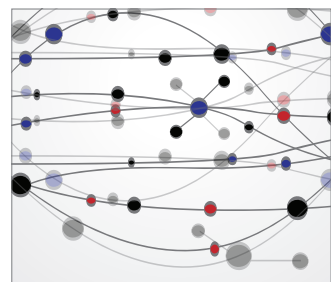

The Scientific World Journal
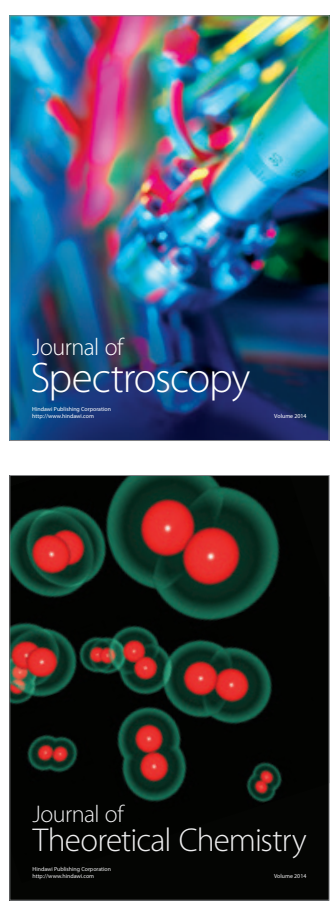
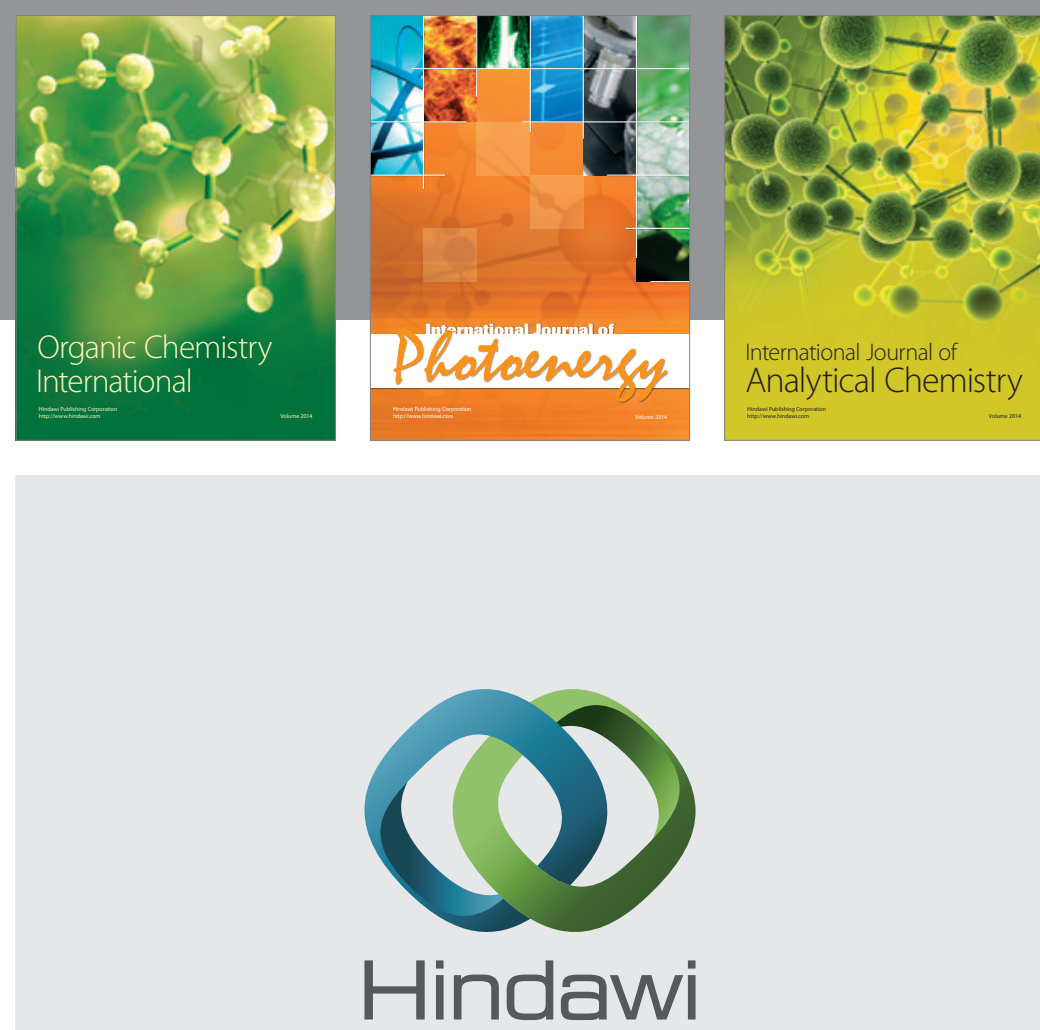

Submit your manuscripts at

http://www.hindawi.com
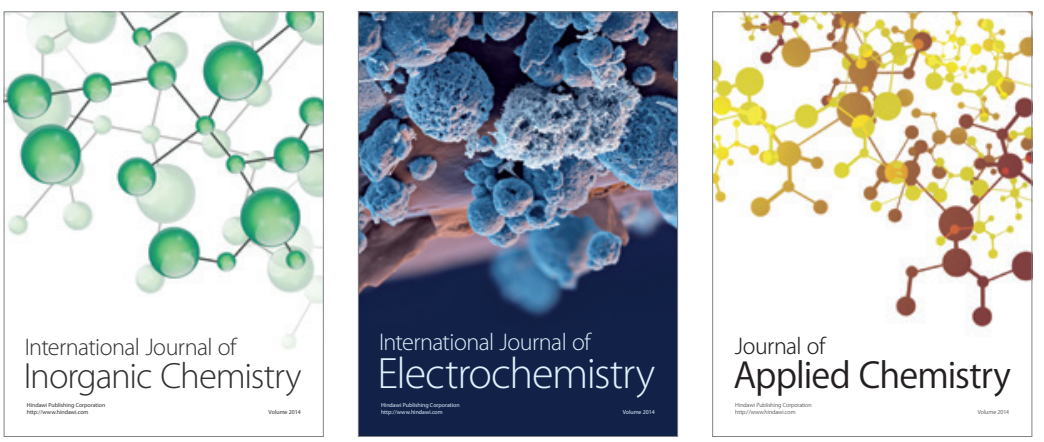

Journal of

Applied Chemistry
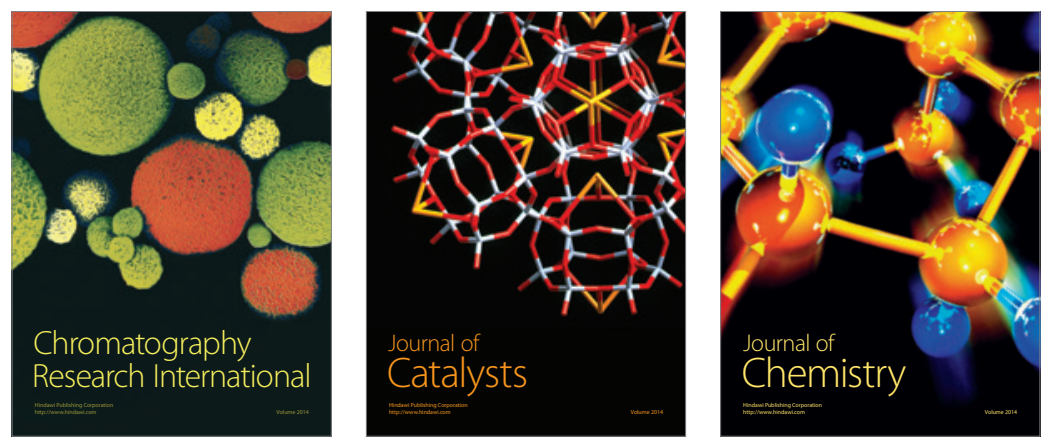
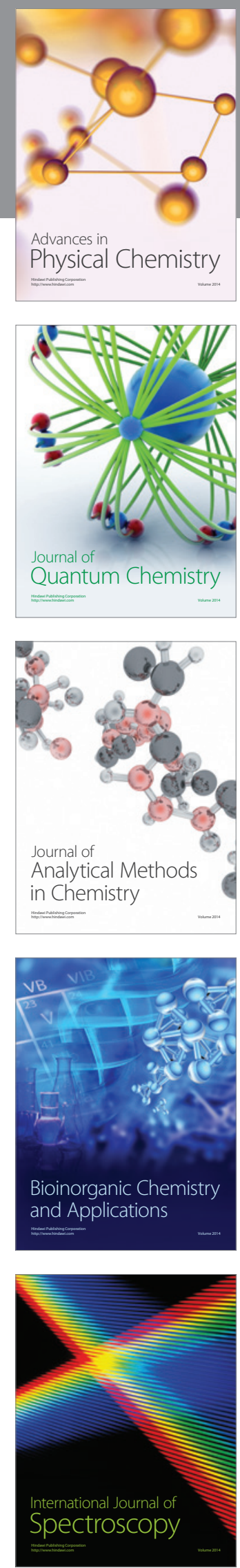